\title{
Influence of stand and site conditions on the quality of digital elevation models underlying New Zealand forests
}

\author{
Michael S Watt ${ }^{*}$, Thomas Adams ${ }^{2}$, Pete Watt ${ }^{3}$ and Hamish Marshall ${ }^{4}$
}

\begin{abstract}
Background: When aerial LiDAR data is used to construct Digital Elevation Models (DEMs) under vegetation, DEM quality will invariably suffer due to attenuation of the laser pulses by the land cover. Although the ratio of ground returns to outgoing pulses ( $G R_{\text {perr }}$ ) is known to vary widely for forest applications, little research has quantified the influence of forest stand structure and site conditions on this ratio. An understanding of how these factors influence $G R_{\text {per }}$ is crucial for the development of accurate DEMs.

Methods: Using an extensive national dataset obtained from New Zealand's plantation forests the objective of this research was to develop a multiple regression model of $G R_{\text {per }}$ that could be used to specify the necessary LiDAR pulse density for development of accurate DEMs.

Results: Within the dataset $G R_{\text {per }}$ averaged $30.5 \%$ ranging from 0.73 to $92.2 \%$. The final model of $G R_{\text {per }}$ included stand age, crop density, non-crop density and slope and accounted for $48 \%$ of the variance in $G R_{\text {per }}$ with root mean square error (RMSE) of 13.9\%. The percentage of ground returns declined exponentially as stand age, crop and non-crop density increased and declined linearly with increases in slope. $G R_{\text {per }}$ was not substantially affected by either the pulse density, stand aspect or whether the stand comprised Pinus radiata or Pseudotsuga menziesii.

Conclusion: The developed model highlights the sensitivity of $G R_{\text {per }}$ to stand and site conditions. This model is likely to be of considerable use in defining the optimal LiDAR pulse density across a range of forest environments.
\end{abstract}

Keywords: ALS, Aerial laser scanning, Ground return density

\section{Background}

High resolution digital elevation models (DEMs) are becoming increasingly important for forest management. Although DEMs may be built from land survey data, they are becoming more commonly constructed using remote sensing techniques. LiDAR has become accepted as providing equivalent accuracy to photogrammetry and interferometric synthetic aperture radar (IFSAR) techniques on open ground and is superior under vegetation (Lefsky et al. 2002; Hodgson et al. 2003). LiDAR offers a means of deriving digital elevation data over large areas with a very high accuracy in the vertical

\footnotetext{
* Correspondence: michael.watt@scionresearch.com

${ }^{1}$ Scion, PO Box 29237, Fendalton, Christchurch, New Zealand

Full list of author information is available at the end of the article
}

coordinate, ranging between 10 and $15 \mathrm{~cm}$ (Baltsavias 1999; Guangping 1998; Wack et al. 2003; Wack and Stelzl 2005).

The presence of vegetation reduces the ability of any remote sensing to detect the ground to some degree. LiDAR manufacturers have attempted to reduce this influence with multi-return and waveform LiDAR, which are capable of either identifying multiple echoes per laser pulse, or recording the entire waveform that may be post-processed to the same effect. Weak ground signals due to attenuation from vegetation stand a better chance of being detected with technological advances in LiDAR receivers.

\section{勿}

C 2013 Watt et al.; licensee Springer. This is an Open Access article distributed under the terms of the Creative Commons Attribution License (http://creativecommons.org/licenses/by/2.0), which permits unrestricted use, distribution, and reproduction in any medium, provided the original work is properly cited. 
A strong determinant of DEM quality is the percentage of ground returns $\left(G R_{\text {per }}\right)$, which is determined from the following equation,

$$
G R_{\text {per }}=100 \frac{\lambda_{\mathrm{GR}}}{\lambda_{\mathrm{p}}} .
$$

where $\lambda_{\mathrm{GR}}$ and $\lambda_{\mathrm{p}}$ are, respectively, the densities of ground returns and incident pulses. For the same incident pulse density as $G R_{\text {per }}$ increases features are increasingly well defined, reducing the magnitude of errors. If the minimum ground return density required for an accurate DEM $\left(\lambda_{\text {GRmin }}\right)$ is known, the required $\lambda_{\mathrm{p}}$ to achieve this $\lambda_{\text {GRmin }}$ can be determined from an estimate of $G R_{\text {per }}$ using the following equation,

$$
\lambda_{\mathrm{p}}=\lambda_{\mathrm{GRmin}} \frac{100}{G R_{\text {per }}} \text {. }
$$

Many end users of DEMs are unaware of the issues surrounding the quality of the underlying height data and the influence of errors on derived calculations such as slope, aspect (Smith et al. 2005) or canopy height models (Clark et al. 2004). As described in Yu et al. (2005) the quality of LiDAR-derived DEMs is influenced by a number of factors, that can be grouped into the following four categories: errors caused by the laser system (e.g. laser system and GPS), errors due to data characteristics (e.g. first/last pulse, point density, flight height, scan angle), errors created during data processing (e.g. filtering process) and errors due to the characteristics of the target (e.g. type of terrain, density of the canopy). The first three categories can largely be controlled by the data provider and much research has been devoted to optimising these aspects (see Discussion in Yu et al., 2005).

The characteristics of the target, which cannot be controlled by the data provider, have been found to have a strong influence on DEM accuracy and $G R_{\text {per }}$. Terrain morphology, season of capture, stand and understory density, stand age, canopy cover and forest species have all been shown to be important determinants of the DEM accuracy (Naesset 2002; Naesset and Okland 2002; Hodgson et al. 2003; Reutebuch et al. 2003; Hyyppa et al. 2005). $G R_{\text {per }}$ generally decreases with increases in stocking and canopy cover and has been found to decline to values as low as $1.1 \%$ in high density sugi (Cryptomeria japonica D. Don) forests (Takahashi et al. 2005). Information on how target characteristics influence $G R_{\text {per }}$ is of interest as once this is known the number of pulses required to produce an accurate DEM can be determined.

Although many of the target characteristics affecting $G R_{\text {per }}$ and DEM accuracy have been identified little research has developed models that can predict $G R_{\text {per }}$ as a function of key factors. Development of accurate models of $G R_{\text {per }}$ require extensive and uniform datasets covering wide ranges in stand conditions so that functional forms can be adequately characterised. For a meaningful study, other important factors that influence DEM accuracy, such as the laser system, flight specifications, data characteristics and data processing steps should be maintained constant to mitigate their influence. These characteristics were part of a recently acquired LiDAR dataset that covers the entire extent of New Zealand's predominantly Pinus radiata D. Don resource. Using this dataset the objective of this research was to develop a model of $G R_{\text {per }}$ that is sensitive to stand structure and topography.

\section{Methods}

\section{Dataset used}

The dataset used was from a national inventory of planted forests undertaken to measure and monitor temporal change in national carbon stocks. This inventory was undertaken to enable New Zealand to meet its obligations under the Kyoto Protocol and the United Nations Framework Convention on Climate Change (Beets et al. 2010).

The vast majority of plots (361 plots, 92\%) were established within Pinus radiata stands with a lesser number in stands of Pseudotsuga menziesii (20 plots, $5 \%)$. As plots in stands of other species comprised less than $3 \%$ of the total, these were excluded from the analysis as replication was inadequate to test for a species effect in these plots. After these exclusions, a total of 381 plots were available for the modelling. The distribution of these plots is shown in Figure 1.

In stands established after 1990 circular plots with an area of 0.06 ha were installed between June and September 2008 using a regular systematic $4 \mathrm{~km}$ grid. In stands established prior to 1990 , plots of 0.06 ha were installed during 2010 on a complete $8 \mathrm{~km}$ grid. Field plot centres were located using a 12-channel differential GPS to within $\pm 3 \mathrm{~m}$.

The LiDAR survey was flown using a Cessna 207 aircraft in February 2008 (for the post-1990 forests) and 2010 (for the pre-1989 forests) using a small footprint $(\sim 0.20 \mathrm{~m})$ Optech ALTM 3100EA system integrated with a Rollei AIC digital camera. Table 1 summarises the LiDAR settings used to achieve first return densities of at least 3 returns $\mathrm{m}^{-2}$. The digital camera was used in tandem with the LiDAR sensor. The resulting colour photography had a ground resolution of $0.2 \mathrm{~m}$ and a forward overlap of 30 percent. The system also utilised an Applanix 510 Position and Orientation System (POS) that uses the GPS and inertial measurement unit (IMU) sensors, and a GPS-based computer controlled navigation system.

\section{LiDAR processing}

LiDAR data was provided by the supplier classified as ground and non-ground returns. The classification was 


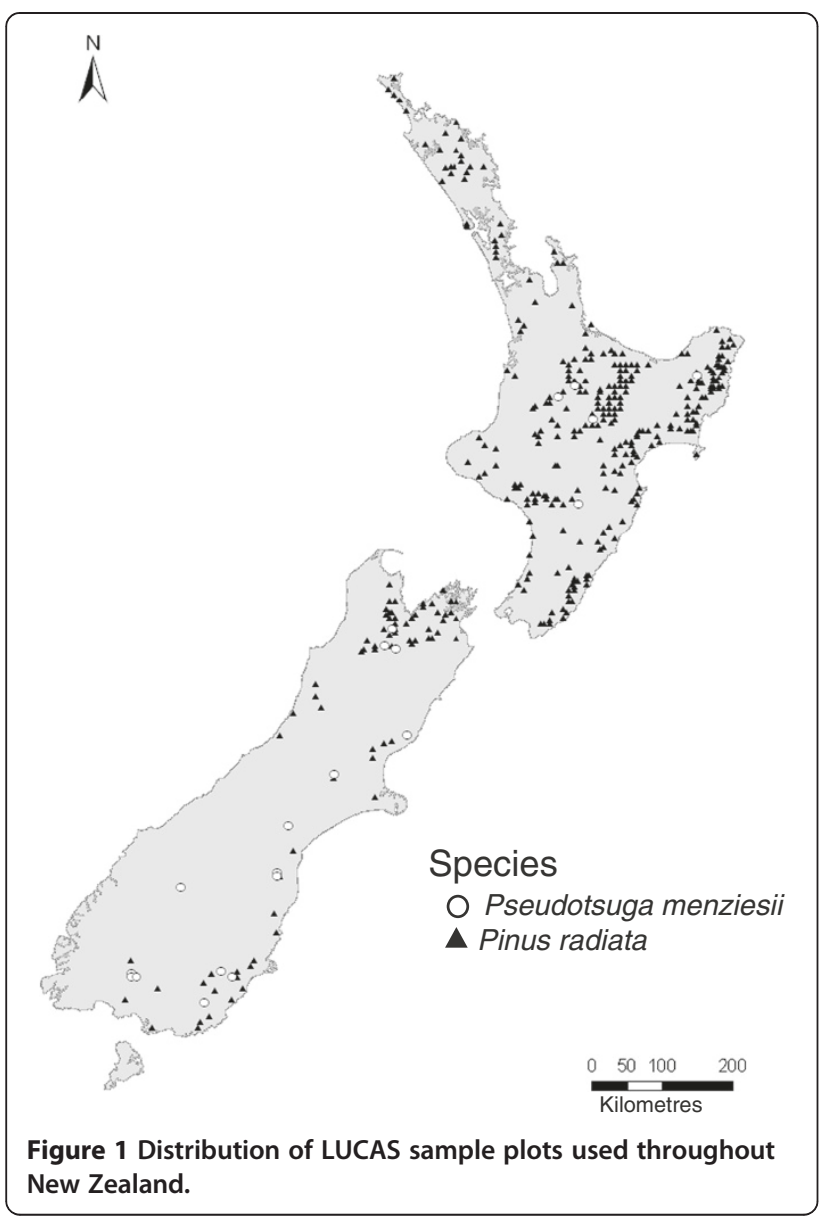

undertaken using Terra-Scan software with the algorithm described by Axelsson (2000). Manual identification of breaklines by skilled operators was also included to improve DEM quality. These classified ground returns were used to construct a DEM by connecting them into a Triangulated Irregular Network (TIN), and then linear interpolation onto a regular grid. As this software commonly underestimates the proportion of ground returns (as in general a false-negative will have a lesser effect on

Table 1 Summary of key LiDAR settings for the dataset collected

\begin{tabular}{lc}
\hline Variable & Value \\
\hline Wavelength $(\mathrm{nm})$ & 1064 \\
Scan angle (deg.) & \pm 6 \\
Pulse frequency $(\mathrm{kHz})$ & 70 \\
Scan frequency $(\mathrm{Hz})$ & 53 \\
Footprint diameter $(\mathrm{m})$ & 0.27 \\
Ground speed $\left(\mathrm{km} \mathrm{hr}^{-1}\right)$ & 194 \\
Flying height $(\mathrm{m})$ & 1200 \\
\hline
\end{tabular}

DEM accuracy than a false-positive), ground returns were deemed to be any return below - or less than $0.2 \mathrm{~m}$ above - this surface.

All returns from each pulse can be identified by an individual time code attached to each record. This enables us to note the exact number of pulses (as well as returns and ground returns) incident over an area. Selection of pulses and returns in a 0.06 ha plot with a differentiallycorrected GPS plot centre was performed using the mathematical scripting environment Matlab (Mathworks, Natick, Massachusetts, U.S.A.). Metrics determined for each plot were number of ground classified returns, number of returns within $0.2 \mathrm{~m}$ of the ground surface, number of pulses and number of returns. $G R_{\text {per }}$ was defined as the ratio of number of returns classified as ground (or within $0.2 \mathrm{~m}$ ) to the total number of pulses, over the plot area (0.06 ha).

\section{Field measurements, aspect, slope}

Stand age for each plot was recorded. Plot measurements relevant to this study included crop and non-crop stand density, with the latter categorised into a range of diameter categories (see Table 2 for classes). Slope and aspect were measured in the field using an inclinometer and compass. Slope, which was measured in degrees, was defined as the average of the maximum gradient at the plot centre, and the gradient at ninety degrees to that.

\section{Analysis}

Models used to predict $G R_{\text {per }}$ were generated using SAS (SAS-Institute-Inc. 2000) by the non-linear modelling procedure, PROC NLIN. This procedure was used as there was non-linearity in this model and PROC NLIN is able to accommodate a range of linear and non-linear functional forms. Variables were introduced sequentially into each model starting with the variable that exhibited the strongest correlation, until further additions were either (i) not significant, (ii) not biologically reasonable or (iii) did not markedly improve model precision.

Variable selection was undertaken manually, and plots of residuals were examined prior to variable addition to ensure that the variable was included in the model using the least biased functional form.

Model precision was determined using the coefficient of determination $\left(R^{2}\right)$ and the root mean square error (RMSE). Model bias was determined through plotting predicted $G R_{\text {per }}$ against measured $G R_{\text {per }}$ and residual values (measured $G R_{\text {per }}$ - predicted values) against predicted $G R_{\text {per }}$ and all independent variables in the model. Model generality was assessed through plotting residual values against a number of key variables not included in the model. 
Table 2 Mean range and summary statistics for variables used in analyses

\begin{tabular}{|c|c|c|c|c|}
\hline Term & Mean & Range & $R$ & $P$-value \\
\hline Age (years) & 13.7 & $0-38$ & -0.30 & $<0.0001$ \\
\hline Stand density -all (stems ha ${ }^{-1}$ ) & 872 & $17-11,183$ & -0.37 & $<0.0001$ \\
\hline Crop stand density (stems ha ${ }^{-1}$ ) & 434 & $0-2,283$ & -0.14 & 0.0048 \\
\hline Non-crop stand density $\left(S_{n c}\right)-$ all $\left(\right.$ stems ha $\left.{ }^{-1}\right)$ & 438 & $0-10,833$ & -0.34 & $<0.0001$ \\
\hline$S_{n c}:$ Diameter $(D)>250 \mathrm{~mm}\left(\right.$ stems ha $\left.{ }^{-1}\right)$ & 7.1 & $0-483$ & -0.14 & 0.0058 \\
\hline$S_{\mathrm{nc}}: D>275 \mathrm{~mm}\left(\right.$ stems ha $\left.{ }^{-1}\right)$ & 5.2 & $0-433$ & -0.13 & 0.013 \\
\hline$S_{n c}: D>300 \mathrm{~mm}\left(\right.$ stems $\left.\mathrm{ha}^{-1}\right)$ & 3.5 & $0-367$ & -0.12 & 0.025 \\
\hline$S_{\mathrm{nc}}: D>350 \mathrm{~mm}($ stems ha-1) & 1.9 & $0-267$ & -0.11 & 0.040 \\
\hline$\left.S_{\mathrm{nc}}: D>500 \mathrm{~mm}_{(\text {stems ha }}{ }^{-1}\right)$ & 0.39 & $0-50$ & -0.11 & 0.036 \\
\hline$S_{\mathrm{nc}}: D>750 \mathrm{~mm}\left(\right.$ stems ha $\left.{ }^{-1}\right)$ & 0.09 & $0-17$ & -0.07 & 0.18 \\
\hline$S_{\mathrm{nc}}: D>1000 \mathrm{~mm}\left(\right.$ stems ha $\left.{ }^{-1}\right)$ & 0.04 & $0-17$ & -0.05 & 0.29 \\
\hline Aspect (०) & 185 & $0-359$ & -0.01 & 0.80 \\
\hline Slope $\left({ }^{\circ}\right)$ & 16.9 & $0.2-44.5$ & -0.23 & $<0.0001$ \\
\hline Incident pulse density (pulses $\mathrm{m}^{-2}$ ) & 3.84 & $2.27-10.38$ & -0.05 & 0.32 \\
\hline
\end{tabular}

Shown are summary statistics describing the strength and significance of the relationship with the percentage of ground returns. Shown are the correlation coefficient $(R)$ and $P$-value for simple linear correlations. The total number of plots used in analyses was 381.

\section{Results}

\section{Data range}

Within the dataset $G R_{\text {per }}$ averaged $30.5 \%$ and ranged widely from 0.73 to $92.2 \%$. The greatest percentage of $G R_{\text {per }}$ occurred between $20-30 \%$ and the distribution was right skewed (Figure 2). Although $G R_{\text {per }}$ for Pinus radiata slightly exceeded that of Pseudotsuga menziesii (30.7 vs. $26.9 \%)$ these differences were not significant $(P=0.40)$.

Plots were located within stands aged between 0 and 38 years. They covered virtually all aspects $\left(0-359^{\circ}\right)$ and were located on sites with slopes ranging from flat to very steep (max slope of $45^{\circ}$ ). Crop stocking ranged from $0-2,283$ stems ha $^{-1}$ while non-crop stocking ranged from $0-10,833$ stems ha $^{-1}$ (Table 2).

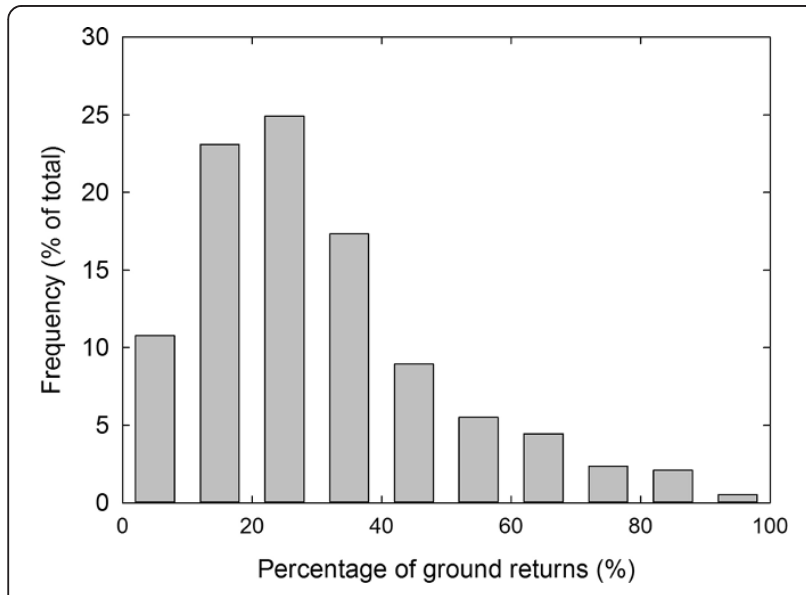

Figure 2 Frequency distribution of the percentage of ground returns.
Correlations between $\mathrm{GR}_{\text {per }}$ and independent variables The percentage of ground returns was most strongly related to total stand density (Figure 3 ), non-crop stand density $\left(S_{\text {nc }}\right)$, crop-density $\left(S_{\mathrm{c}}\right)$, slope and stand age (Figure 3, Table 2). Using a linear model all variables showed significant negative relationships with $G R_{\text {per }}$ as indicated by the negative correlation coefficients (Table 2). For $S_{\text {nc }}$ the strength of the relationship diminished as smaller diameter plants were excluded from the analysis (Table 2). Neither aspect nor the incident pulse density were significantly related to $G R_{\text {per }}$ using simple linear equations (Table 2) or more complex forms with curvilinearity (data not shown).

\section{Regression model to predict $\mathrm{GR}_{\text {per }}$}

The final regression model used to predict $G R_{\text {per }}$ included non-crop stand density $\left(S_{\text {nc }}\right)$, age, crop stand density $\left(S_{\mathrm{c}}\right)$ and slope. The final model formulation was described by,

$$
\begin{aligned}
G R_{\mathrm{per}}= & \mathrm{a} \exp \left(-\mathrm{b} S_{\mathrm{nc}}\right)+\mathrm{c} \exp (-\mathrm{d} \text { age }) \\
& +\mathrm{e} \exp \left(-\mathrm{f} S_{\mathrm{c}}\right)+\mathrm{g} \text { slope }
\end{aligned}
$$

using parameter values given in Table 3 . All variables within the model were highly significant (Table 3 ) and the final model accounted for $48 \%$ of the variance in the dataset with root mean square error (RMSE) of $13.9 \%$. Although total stand density was more strongly related to $G R_{\text {per }}$ than either of the component stockings $\left(S_{\text {no }}, S_{\mathrm{c}}\right)$ the component stockings were used in the final model as the combination of $S_{\mathrm{nc}}$ and $S_{\mathrm{c}}$ resulted in a more precise model than use of only total stand density. Predicted values of $G R_{\text {per }}$ using the final model exhibited little 


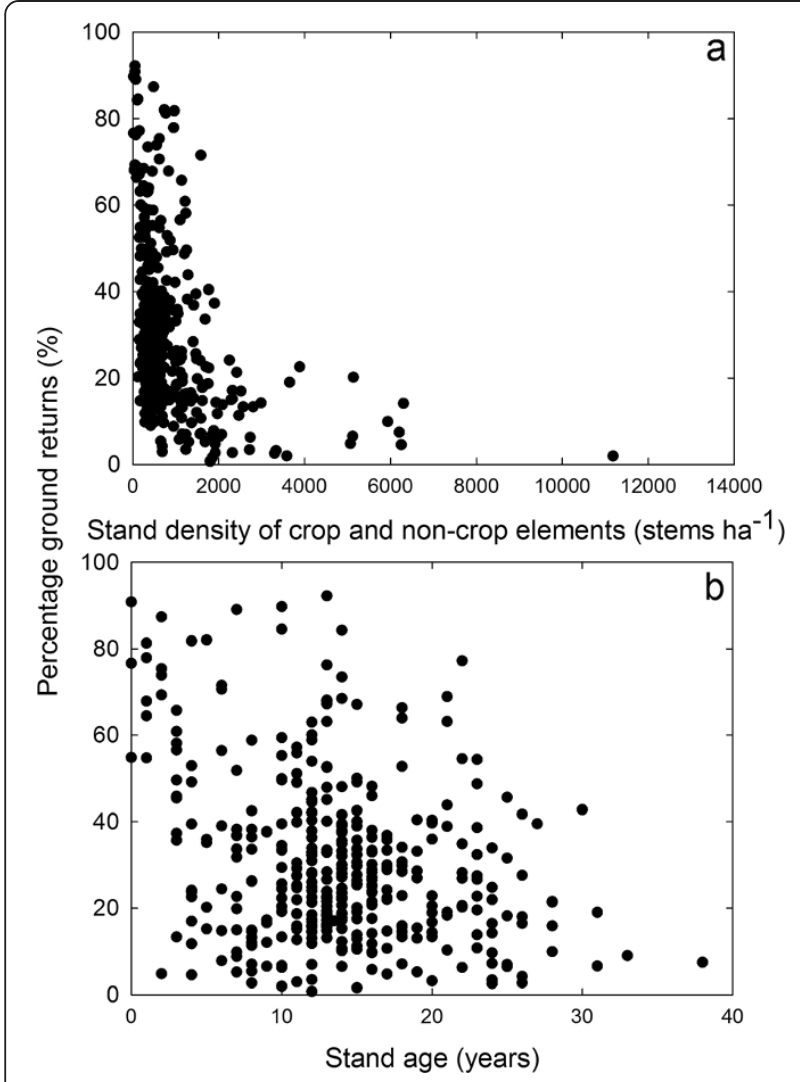

Figure 3 Relationship between percentage of ground returns and (a) stand density of crop and non-crop elements and (b) stand age.

apparent bias against actual values (Figure 4). Residual values for the model exhibited little apparent bias against any of the variables included in the model or aspect (data not shown). Examination of residual values showed species had little effect on the relationship and inclusion of a term for species was not significant (at $P=0.05$ ).

Partial response functions, generated by holding all model terms at average values, apart from the variable shown, are illustrated in Figure 5. These functions show that $G R_{\text {per }}$ declined exponentially with stand age, and

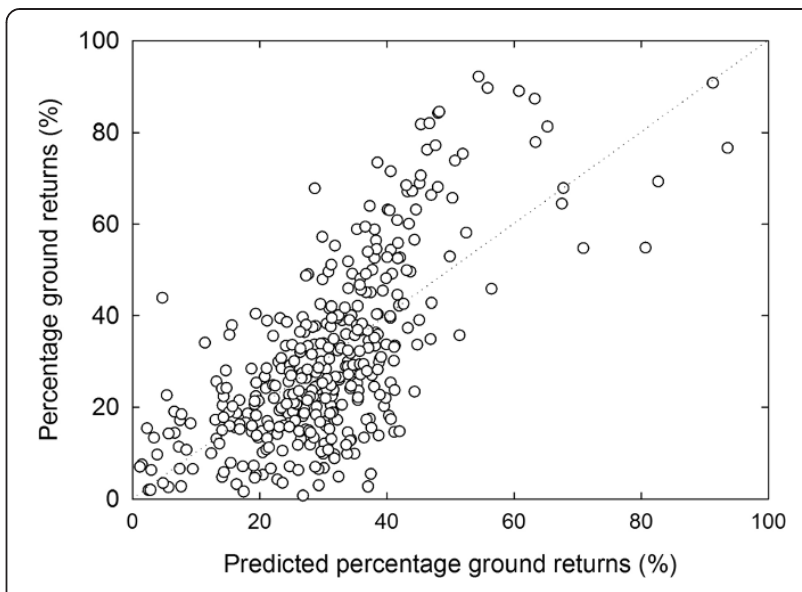

Figure 4 Relationship between predicted and actual percentage ground returns.

both crop and non-crop stand density. There was a linear decline in $G R_{\text {per }}$ with slope. $G R_{\text {per }}$ was most sensitive to stand age, as demonstrated by the considerable reduction in $G R_{\text {per }}$ over the first 20 years, from ca. $61 \%$ to $15 \%$. However, at stand ages above 20 years little decline from $15 \%$ was observed (Figure 5).

As a DEM is usually generated at harvest, Table 4 shows the percentage of ground returns around varying slopes, and crop stand densities, at an average harvest age of 28 years for $P$. radiata. Note that little change would be expected if harvest age was earlier than this as $G R_{\text {per }}$ was found to be generally insensitive to stand age above an age of 20 years (Figure 5). As $G R_{\text {per was rela- }}$ tively invariant to crop stand density above a stand density of 1,000 stems ha ${ }^{-1}$, (Figure 5) no values are shown at stand densities above these. Values are shown for a mean non-crop stand density of 438 stems $^{-1} \mathrm{~h}^{-1}$ and the most common non-crop stand density of 0 stems $\mathrm{ha}^{-1}$ as this latter stand density represented $48 \%$ of observations in the dataset.

Results show a wide range in $G R_{\text {per }}$ from $40 \%$ under the lowest slope, crop and non-crop stand densities to

Table 3 Summary of statistics for the final regression model

\begin{tabular}{|c|c|c|c|c|c|}
\hline Parameter & Value & Variable & Units & $R^{2}$ & Significance \\
\hline $\bar{a}$ & 27.899 & Stand density of non-crop stems & stems ha-1 & $0.17(0.17)$ & $602.77^{* * *}$ \\
\hline$b$ & 0.00110 & & & & \\
\hline$c$ & 47.1411 & Age & years & $0.16(0.33)$ & $47.1^{* * *}$ \\
\hline$d$ & 0.1744 & & & & \\
\hline e & 28.3712 & Stand density of crop stems & stems ha ${ }^{-1}$ & $0.10(0.43)$ & $33.0^{* * *}$ \\
\hline$f$ & 0.00348 & & & & \\
\hline$g$ & -0.5863 & Stand slope & degrees & $0.05(0.48)$ & $39.4^{* * *}$ \\
\hline
\end{tabular}

Parameter values are shown for the model described in Equation 3. Also shown are the partial and cumulative (in brackets) coefficient of determination $\left(R^{2}\right)$ for each variable. For the significance category the $F$ values and $P$ categories from an $F$-test, are shown for each variable, with asterisks $* * *$ representing significance at $P<0.001$. 


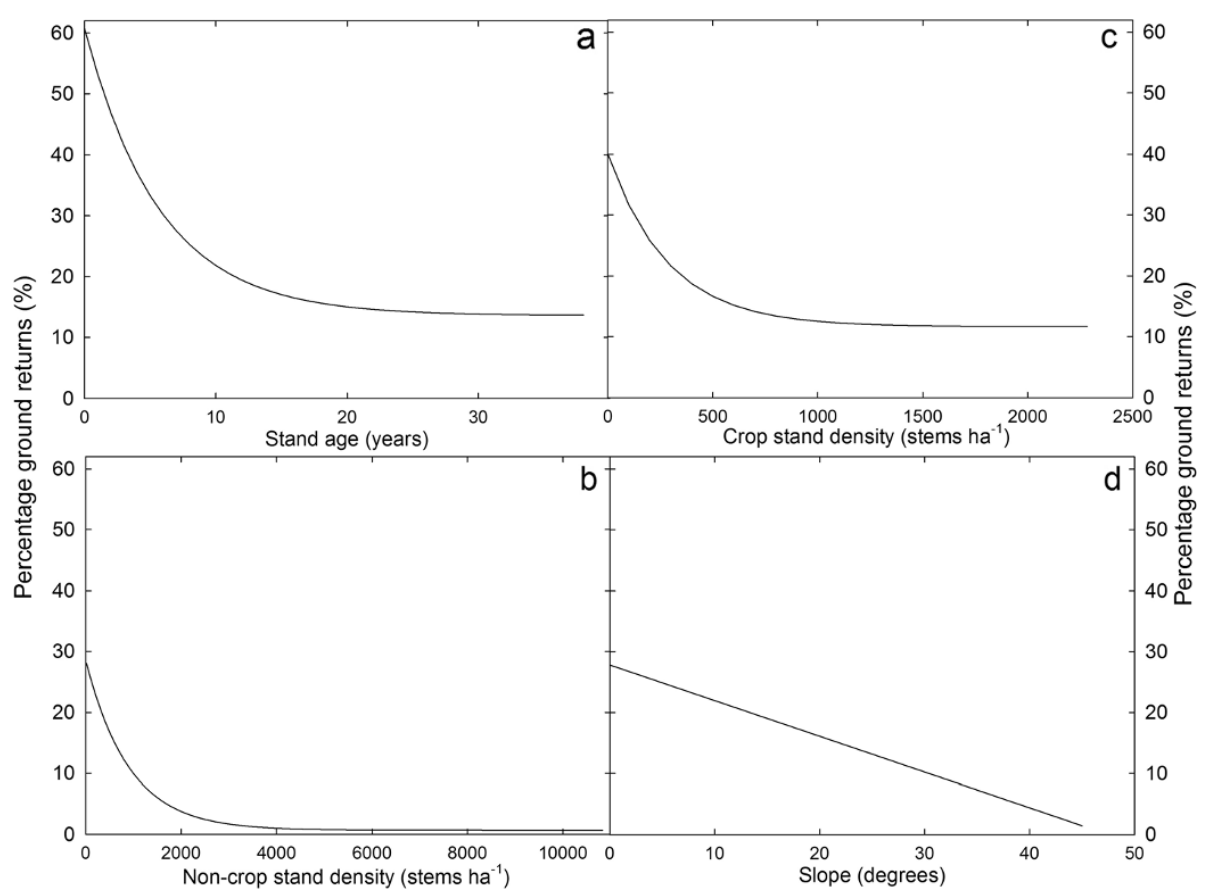

Figure 5 Partial response functions showing variation in percentage ground returns as a function of (a) stand age, (b) non-crop stand density, (c) crop stand density and (d) slope.

$0.7 \%$ for high values of crop stand densities and slope under mean values of non-crop stand densities. It should be noted that the predicted values were constrained to the lowest value in the dataset of $0.7 \%$.

Assuming a minimum of 0.2 ground returns $\mathrm{m}^{-2}$ is required for developing an engineering grade DEM, the predicted $G R_{\text {per }}$ in Table 4 can be used to formulate broad guidelines for development of an accurate DEM.
Table 5 shows recommended minimum pulse densities across a range of stand conditions.

Table 5 shows a wide range in minimum pulse densities. For stands with no non-crop element values are less than 7 pulses $\mathrm{m}^{-2}$ under all combinations of slope and crop stand densities. For stands with an average non-crop stand densities minimum pulse densities are relatively low for low crop stand densities and slopes,

Table 4 Percentage of ground returns as a function of slope, crop stand density for the mean non-crop stand density (438 stems ha ${ }^{-1}$ ) and the most common non-crop stand density (0 stems ha ${ }^{-1}$ )

\begin{tabular}{|c|c|c|c|c|c|c|c|c|}
\hline \multirow{3}{*}{ Slope } & \multicolumn{4}{|c|}{ Non-crop stand density of 0 stems ha ${ }^{-1}$} & \multicolumn{4}{|c|}{ Non-crop stand density 438 stems ha ${ }^{-1}$} \\
\hline & \multicolumn{4}{|c|}{ Crop stand density } & \multicolumn{4}{|c|}{ Crop stand density } \\
\hline & 250 & 500 & 750 & 1000 & 250 & 500 & 750 & 1000 \\
\hline 0 & 40 & 33 & 30 & 29 & 29 & 23 & 20 & 18 \\
\hline 5 & 37 & 30 & 27 & 26 & 27 & 20 & 17 & 16 \\
\hline 10 & 34 & 27 & 24 & 23 & 24 & 17 & 14 & 13 \\
\hline 15 & 31 & 24 & 22 & 20 & 21 & 14 & 11 & 10 \\
\hline 20 & 28 & 22 & 19 & 17 & 18 & 11 & 8 & 7 \\
\hline 25 & 25 & 19 & 16 & 14 & 15 & 8 & 5 & 4 \\
\hline 30 & 23 & 16 & 13 & 12 & 12 & 5 & 2 & 1 \\
\hline 35 & 20 & 13 & 10 & 9 & 9 & 2 & 0.7 & 0.7 \\
\hline 40 & 17 & 10 & 7 & 6 & 6 & 0.7 & 0.7 & 0.7 \\
\hline 45 & 14 & 7 & 4 & 3 & 3 & 0.7 & 0.7 & 0.7 \\
\hline
\end{tabular}

All values are shown for the mean New Zealand rotation length of 28 years. Note that a minimum value of $0.7 \%$ was assumed for $G R_{\text {per }}$ as this was the lowest value recorded in the LUCAS dataset. 
Table 5 Minimum pulse density (pulses $\mathrm{m}^{-2}$ ) required to produce at least $\mathbf{0 . 2}$ ground returns $\mathrm{m}^{-2}$ as a function of slope, crop stand density for the mean non-crop stand density (438 stems ha ${ }^{-1}$ ) and the most common non-crop stand density ( 0 stems ha ${ }^{-1}$ )

\begin{tabular}{|c|c|c|c|c|c|c|c|c|}
\hline \multirow{3}{*}{ Slope } & \multicolumn{4}{|c|}{ Non-crop stand density of 0 stems ha ${ }^{-1}$} & \multicolumn{4}{|c|}{ Non-crop stocking 438 stems ha ${ }^{-1}$} \\
\hline & \multicolumn{4}{|c|}{ Crop stand density (stems ha ${ }^{-1}$ ) } & \multicolumn{4}{|c|}{ Crop stand density (stems ha ${ }^{-1}$ ) } \\
\hline & 250 & 500 & 750 & 1000 & 250 & 500 & 750 & 1000 \\
\hline 0 & 0.5 & 0.6 & 0.7 & 0.7 & 0.7 & 0.9 & 1.0 & 1.1 \\
\hline 5 & 0.5 & 0.7 & 0.7 & 0.8 & 0.7 & 1.0 & 1.2 & 1.3 \\
\hline 10 & 0.6 & 0.7 & 0.8 & 0.9 & 0.8 & 1.2 & 1.4 & 1.5 \\
\hline 15 & 0.6 & 0.8 & 0.9 & 1.0 & 1.0 & 1.4 & 1.8 & 2.0 \\
\hline 20 & 0.7 & 0.9 & 1.1 & 1.2 & 1.1 & 1.8 & 2.5 & 2.9 \\
\hline 25 & 0.8 & 1.1 & 1.3 & 1.4 & 1.3 & 2.5 & 4.0 & 5.0 \\
\hline 30 & 0.9 & 1.3 & 1.5 & 1.7 & 1.7 & 4.0 & 10 & 20 \\
\hline 35 & 1.0 & 1.5 & 2.0 & 2.2 & 2.2 & 10 & 27 & 27 \\
\hline 40 & 1.2 & 2.0 & 2.9 & 3.3 & 3.3 & 27 & 27 & 27 \\
\hline 45 & 1.4 & 2.9 & 5.0 & 6.7 & 6.7 & 27 & 27 & 27 \\
\hline
\end{tabular}

All values are shown for the mean New Zealand rotation length of 28 years.

but do increase markedly to 27 pulses $\mathrm{m}^{-2}$ for high slopes and high crop stand densities.

\section{Discussion}

The dataset used in this study was unique as LiDAR measurements were taken under uniform flying conditions and predominantly from a single tree species that occurred across a very diverse set of stand and site conditions. The relative control of LiDAR attributes and tree species within this dataset allowed the impact of stand structure and site conditions on $G R_{\text {per }}$ to be accurately assessed. Response functions between $G R_{\text {per }}$ and independent variables were well defined as variation in stand and site conditions were extremely wide. Findings show that a relatively large proportion of the variation in $G R_{\text {per }}$ could be attributed to stand conditions (age, stand and understory structure) with the site conditions (stand slope) accounting for somewhat less of the variance.

The factors included in the final model have been previously found to have a significant influence on $G R_{\text {per }}$ and DEM quality. Although there is often collinearity between variables, in general DEM error has been shown to increase with increasing canopy stem density, age (Reutebuch et al. 2003; Naesset 2002; Naesset and Okland 2002), and levels of undergrowth (Hyyppa et al. 2005). A decline in DEM quality with increasing slope has also been demonstrated previously (Hyyppa et al. 2005). Our research extends these previous studies by partitioning the importance of each factor on $G R_{\text {per }}$ and describing the functional form between each of the independent variables and $G R_{\text {per. }}$.

The stand level variables included in the final model are likely to be surrogates for the projected leaf area index (that also includes other above ground material such as stems, branches) which has a direct influence on radiation transmitted to the ground, $\left(Q_{\mathrm{i}}\right)$ and therefore $G R_{\text {per. }}$ In a stand with a continuous canopy $Q_{\mathrm{i}}$ is determined by Beers' Law using $\left.Q_{\mathrm{i}}=1-\left(\mathrm{e}^{-\mathrm{k} L}\right) Q_{\mathrm{o}}\right)$ where $Q_{\mathrm{o}}$ is available incident radiation, $k$ is the light extinction coefficient (assumed to be 0.5 for a spherical leaf angle distribution), and $L$ is the leaf area index of the tree and understory canopy. As $Q_{0}$ is determined by the LiDAR specifications and is relatively constant then variation in the percentage of light reaching the ground $\left(Q_{\mathrm{i}} / Q_{\mathrm{o}}\right)$ is largely reliant on $L$, with values declining as $L$ increases. Previous research has shown strong increases in $L$ with increasing values of stand age that approach a plateau following canopy closure (Madgwick et al. 1977; Pinjuv 2006). The increase in $L$ with understory density has also been documented (Watt et al. 2009). Further research should investigate if a more process-based model of $G R_{\text {per }}$ can be developed using variables such as $L$. Although the model developed here was relatively simple and empirical in nature the variables used are easy to obtain. As a result the final model is likely to be widely used.

No significant differences in $G R_{\text {per }}$ were found between the two species included in the final model. In addition the final model demonstrated little bias with respect to either species, and inclusion of a species term did not significantly improve the final model. The model provided insight into the lack of species influence on $G R_{\text {per. }}$. The effect of the substantially higher mean stand density of Pseudotsuga menziesii over Pinus radiata (875 vs. 410 stems ha-1) on $G R_{\text {per }}$ was almost completely offset by a significantly lower non-crop density in the former species (204 vs. 433 stems ha ${ }^{-1}$ ).

Previous research has often described variation in $G R_{\text {per }}$ between different species (Naesset 1997, 2002; 
Takahashi et al. 2005). Our results suggest that these differences are likely to be attributable to variation in one or more of the factors included in the final regression model (stand density, stand age, understory density, stand slope). For comparisons where one or more of the species is deciduous it is also likely that timing of image capture influences variation in $G R_{\text {per }}$ between species (Hyyppa et al. 2005). Further research, using the modelling approach applied here, should investigate whether there is a species effect after accounting for these factors. A lack of a residual species effect on $G R_{\text {per }}$ would allow generalisation of models describing LiDAR penetration through the canopy.

All data were collected with an Optech 3100EA unit, capable of collecting up to four returns per pulse. Flight specifications were a flying altitude of around $1200 \mathrm{~m}$, ground speed of around $194 \mathrm{~km} \mathrm{hr}^{-1}$ and pulse repetition rate of $70 \mathrm{kHz}$. TerraScan software was used, implementing the algorithm in Axelsson (2000). Manual identification of breaklines by skilled operators was also included to improve DEM quality. With this level of specialisation the exact result cannot be expected to apply to other LiDAR units, flying specifications and postprocessing methods, although the relative influence of the target attributes on $G R_{\text {per }}$ (stand density, non-crop stand density, species, age etc.) are still of significant value.

\section{Conclusions}

In summary, stand and site factors were found to have a significant influence on $G R_{\text {per }}$. When combined into a multiple regression model these factors accounted for $48 \%$ of the variance in a national dataset that covered a wide range of stand conditions and broad topographic gradients. As the necessary pulse density for an accurate DEM can be determined from $G R_{\text {per }}$ the developed model is likely to have useful application within forest management. Further research should investigate whether such a modelling approach can be generalised across a broader range of species, environments, LiDAR collection systems and post-processing tools than was included in this study.

\section{Competing interests}

The authors declare that they have no competing interests.

\section{Authors' contributions}

MSW was the primary author, undertook the analysis and prepared the figures. TA undertook the data extraction and contributed to the writing. PW and $\mathrm{HM}$ assisted with the writing and data preparation. All authors read and approved the final manuscript.

\section{Acknowledgements}

We are very grateful to the Ministry for the Environment (MfE) for providing permission to use the data described in this paper. This project was funded within the Intensive Forest Systems project of Future Forests Research Ltd.

\section{Author details}

${ }^{1}$ Scion, PO Box 29237, Fendalton, Christchurch, New Zealand. ${ }^{2}$ Metservice, 30 Salamanca Road, Kelburn, Wellington 6012, New Zealand. ${ }^{3}$ Indufor Asia-
Pacific Ltd, PO Box 105039, Auckland, New Zealand. ${ }^{4}$ Interpine, 99 Sala Street, PO Box 1209, Rotorua 3010, New Zealand.

Received: 4 June 2013 Accepted: 4 June 2013

Published: 13 June 2013

\section{References}

Axelsson, P. (2000). DEM generation from laser scanner data using adaptive tin models. International Archives of Photogrammetry and Remote Sensing, 33, $111-118$.

Baltsavias, EP. (1999). A comparison between photogrammetry and laser scanning. Isprs Journal Of Photogrammetry And Remote Sensing, 54(2-3), 83-94.

Beets, PN, Brandon, A, Fraser, BV, Goulding, CJ, Lane, PM, \& Stephens, PR. (2010). National forest inventories report: New Zealand. In RE McRoberts (Ed.), National forest inventories: pathways for common reporting (pp. 391-410). Germany: Springer: Heidelberg.

Clark, ML, Clark, DB, \& Roberts, DA. (2004). Small-footprint lidar estimation of subcanopy elevation and tree height in a tropical rain forest landscape. Remote Sensing Of Environment, 91(1), 68-89.

Guangping, HE. (1998). Airborne laser survey system: technology and applications. Journal of Geospatial Engineering, 2, 51-55.

Hodgson, ME, Jensen, JR, Schmidt, L, Schill, S, \& Davis, B. (2003). An evaluation of LIDAR- and IFSAR-derived digital elevation models in leaf-on conditions with USGS level 1 and level 2 DEMs. Remote Sensing Of Environment, 84, 295-308.

Hyyppa, H, Xiaowei, Y, Hyyppa, J, Kaartinen, H, Kaasalainen, S, Honkavaara, E, et al. (2005). Factors affecting the quality of DTM generation in forested areas (ISPRS WG III/3, III/4, V/3 workshop "laser scanning 2005", pp. 85-90). the Netherlands: Enschede.

Lefsky, MA, Cohen, WB, Parker, GG, \& Harding, DJ. (2002). LiDAR remote sensing for ecosystem studies. Bioscience, 52, 19-30.

Madgwick, HA, Jackson, DS, \& Knight, PJ. (1977). Above-ground dry matter, energy, and nutrient contents of trees in an age series of Pinus radiata plantations. New Zealand Journal of Forestry Science, 7, 455-468.

Naesset, E. (1997). Estimating timber volume of forest stands using airborne laser scanner data. Remote Sensing Of Environment, 61(2), 246-253.

Naesset, E. (2002). Predicting forest stand characteristics with airborne scanning laser using a practical two-stage procedure and field data. Remote Sensing of Environment, 80(1), 88-99.

Naesset, E, \& Okland, T. (2002). Estimating tree height and tree crown properties using airborne scanning laser in a boreal nature reserve. Remote Sensing of Environment, 79(1), 105-115.

Pinjuv, GL. (2006). Hybrid forest modelling of Pinus radiata D. Don in Canterbury, New Zealand. PhD thesis (p. 198). New Zealand: University of Canterbury

Reutebuch, SE, McGaughey, RJ, Andersen, HE, \& Carson, WW. (2003). Accuracy of a high-resolution lidar terrain model under a conifer forest canopy. Canadian Journal Of Remote Sensing, 29(5), 527-535.

SAS-Institute-Inc. (2000). SAS/STAT User's guide: version 8. Volumes 1, 2 and 3 (p. 3884). Cary, North Carolina: SAS Institute Inc.

Smith, SL, Holland, DA, \& Longley, PA. (2005). Quantifying interpolation errors in urban airborne laser scanning models. Geographical Analysis, 37, 200-224.

Takahashi, T, Yamamoto, K, Miyachi, Y, Senda, Y, \& Tsuzuku, M. (2005). The penetration rate of laser pulses transmitted from a small-footprint airborne LiDAR: a case study in closed canopy, middle-aged pure sugi (Cryptomeria japonica D. Don) and hinoki cypress (Chamaecyparis obtusa Sieb. et Zucc.) stands in Japan. Journal Of Forest Research, 11, 117-123.

Wack, R, \& Stelzl, H. (2005). Laser DTM generation for south-tyrol and 3D visualization. In G Vosselman \& C Brenner (Eds.), Proceedings of the ISPRS workshop laser and 3D visualization (vol. XXXVI, part 3/W19th ed., pp. 85-90). the Netherlands: International Archives of Photogrammetry, Remote Sensing and Spatial Information Sciences. G Vosselman \& C Brenner (Eds.) Proceedings of the ISPRS Workshop Laser Scanning, September 12-14.

Wack, R, Schardt, M, Barrucho, L, Lohr, U, \& Oliveira, T. (2003). Forest inventory for eucalyptus plantations based on airborne laserscanner data. Proceedings of the ISPRS working group III/3 workshop: 3-D reconstruction from airborne laserscanner and InSAR data (vol. XXXIVth ed.). Dresden, Germany: Institute of Photogrammetry and Remote Sensing, Dresden University of Technology Helmholtzstr. part 3/W13.

Watt, MS, Clinton, PW, Parfitt, RL, Ross, C, \& Coker, GWR. (2009). Modelling the influence of site and weed competition on juvenile modulus of elasticity in 
Pinus radiata across broad environmental gradients. Forest Ecology and Management, 258, 1479-1488.

Yu, X, Hyyppa, H, Kaartinen, H, Hyyppa, J, Ahokas, E, \& Kaasalainen, S. (2005). Applicability of first pulse derived digital terrain models for boreal forest studies (Proceedings of the ISPRS WG III/3, III/4, V/3 Workshop "Laser scanning $\left.2005^{\prime \prime}\right)$. Enschede, the Netherlands: Proceedings of the ISPRS WG III/3, III/4, V/ 3 Workshop "Laser scanning 2005".

doi:10.1186/1179-5395-43-5

Cite this article as: Watt et al:: Influence of stand and site conditions on the quality of digital elevation models underlying New Zealand forests. New Zealand Journal of Forestry Science 2013 43:5.

\section{Submit your manuscript to a SpringerOpen ${ }^{\circ}$} journal and benefit from:

- Convenient online submission

- Rigorous peer review

- Immediate publication on acceptance

- Open access: articles freely available online

- High visibility within the field

- Retaining the copyright to your article

Submit your next manuscript at $\gg$ springeropen.com 